\title{
I. On flax-steeping, and its effects on the colour and quality of the flax
}

\section{Gavin Inglis Esq.}

To cite this article: Gavin Inglis Esq. (1818) I. On flax-steeping, and its effects on the colour and quality of the flax, Philosophical Magazine Series 1, 51:237, 3-6, DOI:

10.1080/14786441808637494

To link to this article: http://dx.doi.org/10.1080/14786441808637494

里 Published online: 27 Jul 2009.

Submit your article to this journal $₫$

Џ Article views: 2

Q View related articles $\sqsubset$ 


\section{PHLLOSODHEAT MAGARTE ANTS JOURNAL.}

1. On Flax-steeping, and its Effects on the Colour and Quality of the flax. By Gavin Ixgute, Esq.

\section{To Mr. Tilloch.}

Dian Sir,-Iy you consider the following observations on Hax-steeping worthy of a place in your valuable Magazine, I will thank you to insert them. They are the substance of answers furnished by me to inquiries made upon that subject by G. Thomson, Esci. of the Trustees Office, Edinburgh.

When in Dumbartonshire in 1801 , reducing to practice the process of bieaching by steam, I had a few spindles of yarn given me to prepare for weaving. There was in the sleekness of the threarl something that attracted my attention. Having soaked it orer-night in warm water to prepare it for steaming, I was much surprised at the change of colour, and the quantity of colowring matter dissolved in the water. It was then washed, wrung, and soaked in a weak alkaline ley, and haid for steaming over some brown linens. After sieaming the usual time, the covers were talien off. The yarn was found to have attained a degree of whiteness I never had before observed under similar circumstances. It was washed in the strean so long as any colouring matter came from it, and laid to the grass for two days. I remember well the colour was sich as to impress me with a strong belief that some great and important discorery might be the result of accurately following up the process this flas bad gone through; and I immediately made inquiry of the lady to whom the varn belonged, who informed me she had it from a person she ia amed, in the neighbourhood: to this individual I made the same application, and traced the yarn to have been purchased at a Kilmarnock fair.

Here the matter rested till the next season of lint pulling. I had a particular wish to trace if possible the matter to its source, and conceived the best plan would be to traverse that part of the country, from Stirling towards Kilmarnock. My time was far

Vol.51. No.237. Jan. 1815.

A 2

too 
too limited: but I saw as much as to satisfy myself that the secret with regard to the bleaching, lay entirely in pulling the flax before it was too ripe; and I also found that this great advantage might again be lost by improper watering.

I saw the flax in all its stages, from the pulling to the drying after watering; and upon incuiry I uniformly found the greenest pulled was intended for the finest purposes, and that the whitest, flax, after drying, had been watered in the burn. They were very particular in watering, and did not allow it to remain so long in the water as I had been led to helieve necessary, from the practice here; nor did they spread it on the grass after watering, as is the mode in this quarter, but dried it all from the water, by what is termed hutting.

As bleaching alone was my object, $m y$ inquiries respecting the different shades of colour after watering were very particular; and I uniformly found that the white flax had been watered in the burn, and the dark-coloured in ponds dug where water could be most conveniently obtained. When I mention a burn, it must be understood to be a stream so small as to require a dam being necessary to receive the water into a remporary pond to cover the flax.

The succession of clean water, I conceive, prevents the deposition of colouring principles, to be hereafter mentioned, by washing or carrying them away, after being extracted from the flax, which I had afterwards an opportunity of proving, in a pond so constructed, which produced remarkably white flax, while the same flax, from several stagnant ponds dug in the same ground, filled with water from the same spring, was very dark in the colour.

In following up these observations, my situation in life did not then admit of experiments to the extent the importance of the subjeet would have required. I shall, however, narrate these, so far as they extended. The result satisfied me, that the watering of flax must vary with local circminstances, and every where depend on the means afforded by sjprings, streams, moss, or marsh, that may be in the neighbourhood of the flax-field, so long as the present mode of culture is followed; and the colour of the flax after watering very much depend on the following causes:

The ripeness of the flax before pulling.

The state of putridity of the stagnant water.

The minerals the water may contain.

Whether it is steeped in a pourl dug, or one formed by damming a small stream or rill. Or, if a succession of parcels of flax (which is sometimes the case) be watered in the same pond, where every succeeding parcel must partake of the contaminating; dye produced by the fermentation of the former.

In the course of ny observations, I found the quantity and solubility 
solubility of the colouring matter in proportion to the degree of ripeness; and in the ripest, on a principle I never till then knew to have an existence in flax, viz. iron, which may be said to abound in ripe flax.

In unripe flax I found the colouring matter soluble in water; but this matter became less and less soluble, till the water made little or no impression upon it. The time necessary for flax to macerate must in some measure depend on the weather, but more on the state of ripeness than most practitioners seem to be atware of.

In unripe flax the juices of the plant are in a mucilaginous state; hence its solubility in water. If flax is watered in an unripe state, the mucilage, from its solubility, tends greatly to facilitate the process of watering, by promoting the fermentation. But if the flax is allowed to stand on the ground till it has attained a rusty-brown colour, and the seed fully ripened, the juices of the plant are then changed from mucilage to resinous matter, and certainly no longer soluble in water, so far as the resin is concerned, inless assisted by solvents.

In this stage, instead of having a large portion of mucilage to expedite the fermentation, the resin defends the flax for a time agrainst the effects of the water, and the fermentation must proceed by slow degrees; consequently the time necessary to steep flax must vary according to the ripe or unripe state of the flax when pulled. What would sufficiently water unripe flax, would bardly penetrate the outer rind of the ripe; and the time required for the ripe would entirely destroy the other.

The choice (where a choice can be made) of the water, and the ground into which ponds are to be dug, or the rill or stream into which the flax is to be laid, is certainly of the highest importance, for the colour, quantity and quality of the flax.

That very great improvements may be made in the mode of separating the flax from the rind and boon, so as to render that process less offensive, far safer, and equally effectual, I have no doubt whatever. But before promulgating any speculative theory on a subject of such importance to the nation, would it not be laudable in the Honourable Board of Trustees to cause a full series of experiments on a fair scale, to be made and followed up by some persons of skill and observation, which would set the matter at rest, solve all doubts on so important a process, and furnish the farmer and flas-grower with such instructions that he could not err.

The presence of iron in the plant was discovered in my attempts to bleach flax, by different modes, to ascertain whether there existed anv other principle beside mucilage, resin and oil, in what stage the juices became insoluble in water, and to $\Lambda 3$ 
what extent these substances existed, with a view to ascertain the safest strength of alkaline applications to be used in the different processes of bleaching. Alkalies are the common solvents used by bleachers; but I did not conceive them altogether adapted to my present purpose. I took alcohol, and succeeded in bleaching to a very beantiful whiteness fiax in its unripe state and in its early stages; but as the flax ripened, its power lessened. I exposed full ripe flax to the action of alcohol, both in a liquid state and in the state of vapour, till I satisfed myseif of having extracted all the resinous matter; -still a colour remained. I subjected it to the action of an oxymuriate, and was astonished to see the presence of jron so strongly indicated. I took another quantity of this full ripe flax, and boiled it in a ley of prussiate of potash, prepared by calcination of common potash with green whins: from this it was washed, and immersed in oxymuriate of lime, which produced a beautiful light blue. This experiment I repeated till I produced, by apparently the same process, on the unripe flax a beautiful white, and on the full ripe a fine, full, Prussian blue. This explained in a most satisfactory manner many of the phænomena of bleaching I never before could comprehend, and appeared to me a most wonderful work in nature,the formation of a metal in the juices of a plant, whose existence was not detected, by the same means, in the same plant, only fourteen to twenty days younger than where its presence became so manifest.

Tan also exists in flax, and is very soluble in water.

In steeping fiax, the water in the pond becomes impregnated with tan. "he process of fermentation comes on, in the progress of which the iron is acted upon. The iron and tan combine, precipitate, and form an almost indestructible dye.

Thus, by inattention to the steeping of flax, the labour and expense of bleaching are greatly increased. The linen loses much of its strength and durability by the necessary process of bleaching, and festroying a colonr which, by due care, might be prevented from ever fixing itself. With esteem, I remain,

Strathendry Bleachfield, Dear sir, yours sincerely, Dec. 10,1817 .

II. Supplement to Mr. Benwexc's Paper on the Value of increasing Life Anmuities, in our Number for Seplember 1817.

To Mr. Tilloch.

SIR, $-F_{\text {Rom the circumstance of having changed the original }}$ form of the theorems for determining the values of increasing 